11. Goodman E, Daniels SR, Morrison JA, Huang B, Dolan LM. Contrasting prevalence of and demographic disparities in the World Health Organization and National Cholesterol Education Program Adult Treatment Panel III definitions of metabolic syndrome among adolescents. J Pediatr. 2004;145:445-51.
12. Ko GT. Metabolic syndrome or "central obesity syndrome"? Diabetes Care. 2006;29:752.

\title{
Obesity, insulin resistance and the metabolic syndrome
}

\author{
Alan Sinaiko*
}

$T_{\text {heren }}$ here has been a remarkable increase in interest during the past two decades in the relation between cardiovascular risk factors in children and the development of arteriosclerotic cardiovascular disease (ASCVD) and type 2 diabetes in adulthood. Initial studies concentrated on individual factors such as lipids and blood pressure. However, as research in this area has evolved and pediatricians have followed the lead of their colleagues in internal medicine, attention has turned to broader considerations of risk and, in particular, to obesity, insulin resistance and the metabolic syndrome. It is not surprising that these studies are affirming the concept that the roots of ASCVD and type 2 diabetes extend back into childhood.

The relation of obesity to ASCVD in adults is well known. Although children and adolescents do not have overt AS-

CVD, obese children have a cardiovascular risk profile consistent with its early development, i.e., significantly higher blood pressure, triglycerides and fasting insulin and significantly lower HDL-C. ${ }^{1}$ Moreover, the degree of risk increases with increasing obesity. ${ }^{2}$ The result is early deposition of fatty streaks and plaque in adolescent coronary arteries, ${ }^{3}$ and the outcome in adulthood is an increased incidence of premature cardiovascular and all-cause mortality in individuals who were obese adolescents. ${ }^{4}$ Despite a perception in the general population that overweight children tend to become thinner as they go through adolescence and maintain the thinness as they become young adults, longitudinal growth studies have shown a highly significant $(r=0.61)$ correlation in body mass index (BMI) between ages 7 and 24, and have further shown

* MD, Professor, Department of Pediatrics, University of Minnesota, Twin Cities, MN, USA.

Suggested citation: Sinaiko A. Obesity, insulin resistance and the metabolic syndrome. J Pediatr (Rio J). 2007;83(1):3-5.

doi:10.2223/JPED.1585 that BMI at age 7 predicts the ASCVD risk factors at age $24 .^{5}$ The relevance of these findings is of increasing importance to pediatricians, since the prevalence of obesity in children is steadily increasing in all ethnic groups. ${ }^{6}$

The relation of obesity to insulin resistance is also well known, and while insulin resistance is related to the development of ASCVD, its role independent from obesity is not clearly defined. Nevertheless, it has become evident that obesity cannot completely explain the development of insulin resistance. Insulin resistance is not present in all obese individuals; nonobese, nondiabetic individuals can be insulin-resistant; and type 2 diabetes occurs in nonobese individuals. In an attempt to clarify the independent influence of BMI and insulin resistance on the development of cardiovascular risk and type 2 diabetes, we have been conducting a longitudinal study, including euglycemic hyperinsulinemic clamps, in children who were randomly recruited from a public school population of 11-14 year olds. Results from this study are showing that insulin resistance, of itself, is associated with increased levels of cardiovascular risk factors. ${ }^{1}$ When the cohort was divided into two groups according to insulin sensitivity and resistance, the insulin resistant group was found to have significantly higher fasting insulin, triglycerides and lower HDL-C, independent of BMI. And, when the cohort was further divided according to levels of both BMI and insulin resistance, an interaction was uncovered in the obese, insulin resistance group, leading to higher levels of risk factors than would be expected by simply adding together the individual effects of BMI and insulin resistance. This cohort has now been followed to early young adulthood (age range 18-21). Recent studies ${ }^{7}$ have shown that insulin resistance measured at age 13 predicts, independent from BMI, blood pressure and lipids at age 19. Thus, it 
appears that insulin resistance, of itself, is etiologically related to the ultimate development of ASCVD.

As investigation into the relation between obesity and insulin resistance has intensified, certain fat compartments, in particular visceral fat, have been shown to be more functionally active than others. ${ }^{8}$ Visceral fat cells have higher rates of lipolysis than subcutaneous fat cells, resulting in a greater production of free fatty acids, and elevated free fatty acids have been associated with increased insulin resistance. In addition, visceral fat is a prominent source of the adipocytokines Il-6, TNF-a and adiponectin, all of which have been related to insulin resistance. Visceral fat content is highly correlated with waist circumference, suggesting that waist, rather than BMI, may be a better predictor of insulin resistance.

In this issue of Jornal de Pediatria Ferreira et al., ${ }^{9}$ report on the prevalence of the metabolic syndrome in 1,550 Brazil schoolchildren. They found that $8 \%$ of the children were overweight, and $17.3 \%$ of the overweight children had the metabolic syndrome. Although these figures are lower than those reported for Caucasian, Black and Hispanic children in the United States, ${ }^{6,10}$ they show that Brazil is faced with the same high prevalence seen in other countries. The appropriate application of the metabolic syndrome to patient care is still being debated, ${ }^{11}$ but most would agree that it is related clinically to future cardiovascular disease. Although a direct role for insulin resistance in the development and maintenance of the syndrome has not been established, most clinicians believe insulin resistance is directly involved. It might be suggested that obese children without the metabolic syndrome are those without insulin resistance. An issue for pediatrics is how to define threshold values for the factors comprising the system. Most studies in children have arbitrarily modified the published adult standards to select values that are based on pediatric norms. This is a reasonable approach, but longitudinal studies confirming the appropriateness of those values have not yet been published.

The euglycemic hyperinsulinemic clamp is the acknowledged "gold standard" measure of insulin resistance. ${ }^{12}$ In the study by Ferreira et al., the authors use HOMA, a surrogate measure of clamp-derived insulin resistance, to show an apparent link between the metabolic syndrome and insulin resistance. Because the clamp is technologically more complicated and places an increased burden on the patient, including a 2-3 hour stay in a clinical research center, a number of surrogate measures for insulin resistance have been designed. HOMA is one of the most widely used and requires only a fasting blood sample for insulin and glucose. The formula for HOMA is serum glucose $x$ fasting insulin/22.5. However, HOMA does not define insulin resistance in children with any greater accuracy than fasting insulin (the correlation between fasting insulin and HOMA is $>0.95$ ), because glucose is so tightly controlled and its range is so narrow in children that its use in the HOMA formula does not discriminate among individuals. The correlation between either HOMA or fasting insulin and the insulin clamp is low (approximately 0.4-0.5 in most studies), and most investigators today do not believe that HOMA is an accurate measure of insulin resistance in children.

Can fasting insulin be used as a surrogate measure for insulin resistance? Unfortunately, the range of fasting insulin in children is relatively narrow, so that it also lacks the precision required to categorize individuals. However, degree of insulin secretion is relevant to the study of insulin resistance, and fasting insulin levels may be used in other ways. For instance, it has been incorporated by the European Group for the Study of Insulin Resistance into the definition for the metabolic syndrome. ${ }^{13}$ In our studies in children we have incorporated it with triglycerides, HDL-C and blood pressure into an "insulin resistance score" that has been applied in studies of BMI and insulin resistance. ${ }^{1}$ We have found that the score may provide a better picture of overall cardiovascular risk than examination of the individual risk factors.

Physicians caring for children have historically been entrusted with preventing disease during childhood and ensuring normal growth and development prior to adulthood. The soaring prevalence of obesity in childhood coupled with the increase in levels of cardiovascular risk factors and the metabolic syndrome offers another challenge to fulfilling those responsibilities. Although it has been obvious for many years that obesity is associated with cardiovascular risk, the etiologic factors linking obesity to the factors that define the metabolic syndrome have not been identified. Recent data suggest that insulin resistance may be one of those factors. It is hoped that ongoing studies in children will provide the information required to design strategies that can be applied during childhood in order to reduce the incidence of premature ASCVD in adults.

\section{References}

1. Sinaiko AR, Steinberger J, Moran A, Prineas RJ, Vessby B, Basu $S$, et al. Relation of body mass index and insulin resistance to cardiovascular risk factors, inflammatory factors, and oxidative stress during adolescence. Circulation. 2005;111:1985-91.

2. Weiss R, Dziura J, Burgert TS, Tamborlane WV, Taksali SE, Yeckel $\mathrm{CW}$, et al. Obesity and the metabolic syndrome in children and adolescents. N Engl J Med. 2004;350:2362-74.

3. Berenson GS, Srinivasan SR, Bao W, Newman WP 3rd, Tracy RE, Wattigney WA. Association between multiple cardiovascular risk factors and atherosclerosis in children and young adults. The Bogalusa Heart Study. N Engl J Med. 1998;338:1650-6. 
4. Must A, Jacques PF, Dallal GE, Bajema CJ, Dietz WH. Long-term morbidity and mortality of overweight adolescents. A follow-up of the Harvard Growth Study of 1922 to 1935 . N Engl J Med. 1992;327:1350-5.

5. Sinaiko AR, Donahue RP, Jacobs DR Jr., Prineas RJ. Relation of rate of growth during childhood and adolescence to fasting insulin, lipids, and systolic blood pressure in young adults. Circulation. 1999;99:1471-6.

6. Ogden CL, Flegal KM, Carroll MD, Johnson CL. Prevalence and trends in overweight among US children and adolescents, 1999-2000. JAMA. 2002;288:1728-32.

7. Sinaiko AR, Steinberger J, Moran A, Hong CP, Prineas RJ, Jacobs DR Jr. Influence of insulin resistance and BMI at age 13 on systolic blood pressure, triglycerides and HDL-C at age 19. Hypertension. 2006;48:730-6.

8. Montague CT, O'Rahilly S. The perils of portliness: causes and consequences of visceral adiposity. Diabetes. 2000;49:883-8.

9. Ferreira AP, Oliveira CE, França NM. Metabolic syndrome and risk factors for cardiovascular disease in obese children: the relationship with insulin resistance (HOMA-IR). J Pediatr (Rio J). 2007;83:21-6.
10. Cook S, Weitzman M, Auinger P, Nguyen M, Dietz WH. Prevalence of a metabolic syndrome phenotype in adolescents: findings from the third National Health and Nutrition Examination Survey, 1988-1994. Arch Pediatr Adolesc Med. 2003;157:821-7.

11. Kahn R, Buse J, Ferrannini E, Stern M; American Diabetes Association; European Association for the Study of Diabetes. The metabolic syndrome: time for a critical appraisal: joint statement from the American Diabetes Association and the European Association for the Study of Diabetes. Diabetes Care. $2005 ; 28: 2289-304$.

12. Ferrannini E, Mari A. How to measure insulin sensitivity. J Hypertens. 1998;18:895-906.

13. Balkau B, Charles MA. Comment on the provisional report from the WHO consultation. European Group for the Study of Insulin Resistance (EGIR). Diabet Med. 1999;16:442-3.

\title{
The quality of care of very low birth weight babies in Brazil
}

\author{
Fernando C. Barros, ${ }^{1}$ José Luis Diaz-Rossello²
}

$T_{\text {h }}$ ting paper on health services research, analyzing the mortality of very low birth weight (VLBW) babies born in maternity hospitals with neonatal intensive care units (NICU) in 2002-2003, in Fortaleza, Ceará, Brazil. ${ }^{1}$ As the authors rightly state, this birth weight group, although being less than $2 \%$ of the total live births, require a highquality hospital care and account for a substantial and growing proportion of neonatal and infant mortality.

1. Pediatra y epidemiólogo. Consultor, Centro Latinoamericano de Perinatología y Desarrollo Humano (CLAP), Organización Panamericana de la Salud/Organización Mundial de la Salud (OPAS/OMS), Montevideo, Uruguay.

2. Pediatra neonatólogo. CLAP, OPAS/OMS, Montevideo, Uruguay. Profesor, Facultad de Medicina, Universidad de la Republica, Montevideo, Uruguay.

Suggested citation: Barros FC, Diaz-Rossello JL. The quality of care of very low birth weight babies in Brazil. J Pediatr (Rio J). 2007;83(1):5-6.

doi:10.2223/JPED.1586
The paper shows that the neonatal and overall hospital mortality rates of Fortaleza's VLBW babies are much higher than those observed in a network of NICUs in the United States, for all birth weight groups. ${ }^{2}$ Birth weightspecific intrahospital mortality is an indicator of quality of care and this initial comparison with NICUs of a highly developed country may put the target too far. However, the authors also show that the mortality rates in Fortaleza are higher, for all birth weight groups, than those observed in Montevideo, Uruguay. ${ }^{3}$ Here we should be much more concerned about the magnitude of our avoidable deaths, considering that there are no relevant differences in the available technology and human resources for the care of newborns between the two cities.

After the publication of these interesting results, what should be the next steps to identify gaps in the quality of care in Fortaleza's NICUs in order to prevent avoidable deaths? One first element would be to compare the units participating 